\title{
ANTROPOLOGIAS, ARTES E POLÍTICA: \\ ENGAJAMENTOS E ENCONTROS
}

Paulo Raposo ${ }^{1}$

\section{Pontos de partida para uma antropologia engajada}

Desde há algum tempo que venho a assumir-me como participante de um modo de fazer antropologia que definiria por engajado. Meu percurso pessoal de cidadão comprometido, muitas vezes até como ativista político, e simultaneamente, a minha formação e interesse por artes performativas talvez tenham contribuído decisivamente para isso. Na verdade, tendo sido um adolescente contaminado pela revolução dos cravos em Portugal, desde cedo me envolvi em movimentos sociais, em atividades políticas estudantis, participando em associações e estruturas culturais com intervenção social ou de protesto político. Isso levou-me primeiro ao teatro e logo quase de seguida à antropologia e procurei cruzar esses campos ao longo do meu percurso académico sempre sob um pano de fundo político. A minha cidadania ativa ganhou um segundo fôlego quando, em 2009, chegado do Brasil, me empenhei militantemente em atividade de intervenção política a propósito da intervenção da Troika em Portugal e dos chamados novíssimos movimentos sociais (Juris, Feixa e Pereira, 2012). Essa consciência política claramente permeou desde aí a minha atividade académica também. E, nesse sentido, envolvi-me em um conjunto de propostas de diálogo, interceção, instigação e engajamento num itinerário que me levava constantemente a estabelecer articulações entre dentro e fora da academia.

Obviamente pensar sobre uma antropologia ativista, implica refletir não apenas nos seus potenciais, mas também nos seus limites. De qualquer forma, entendo que um bom ponto de partida é perceber que todo o conhecimento é político, uma vez que a produção ou o enquadramento do conhecimento tem sempre efeitos políticos. Charles Hale, um dos autores que mais comentou esta dimensão do perfil ativista do antropólogo, sugere que estes "têm uma dupla lealdade - à academia e a uma luta política que, muitas

\footnotetext{
${ }^{1}$ Instituto Universitário de Lisboa, Portugal. E-mail: pjp.raposo@gmail.com ORCID id: https://orcid.org/0000-0003-0857-9785
} 
vezes abrange, mas chega sempre mais além do cenário universitário" (Hale, 2006:100, trad.minha). Hale diferenciava uma certa antropologia de crítica cultural de uma outra mais militante. Acrescentava que os antropólogos que fazem "crítica cultural" estão mais empenhados nos ideais intelectuais do que na promulgação de mudanças, e afirmam que a investigação ativista "é simplista, sem problemas e sub-teorizada" (idem:101, trad. minha). Embora Hale nunca negue a complexidade de habitar e trabalhar dentro destas "duplas lealdades", o seu argumento é que a investigação ativista é enriquecida justamente pela sua existência "no meio da tensão entre os ideais utópicos e a política prática" (idem:100, trad. minha). Por isso, me alinho cada vez mais confortavelmente nesta proposta definicional de Charles Hale para uma investigação ativista entendendo-a como "um método através do qual afirmamos um alinhamento político com um grupo organizado de pessoas em luta, e permitimos o diálogo com elas para moldar cada fase do processo, desde a conceção do tema da investigação, à recolha de dados, à verificação e divulgação dos resultados". (idem: 97, trad. minha).

Emma Kowal, uma antropóloga médica australiana, ainda que secundando esta abordagem de Hale, alude a certos constrangimentos relevantes que nos fazem pensar no potencial e nos limites das pesquisas ativistas. A autora baseia-se ${ }^{2}$ nas reflexões de um antropólogo libanês, Ghassan Hage, da Universidade de Melbourne, que num paper com o curioso título "Hating Israel in the Field: On ethnography and political emotions" exprime as convulsões e constantes alterações de engajamento e de posicionamento que foi sentindo ao longo da sua inserção em meio académico e no decurso da pesquisa de campo. Basicamente Hage (2009) descreve como, sendo um jovem que cresceu no Líbano, era muito pró-Israel - uma posição comum num ambiente libanês cristão. Contudo, através de leituras marxistas durante a sua graduação na Austrália nos anos 70, transformou-se num "anti-israelita" e num "esquerdista" (embora esta fosse uma posição sobretudo intelectual). A pesquisa de terreno trouxe-lhe posteriormente ainda a questão emocional de um posicionamento pró-palestiniano mas não necessariamente de uma "verdade" palestiniana. Mais tarde, ao começar a ler Bourdieu, veio a refletir de forma bastante crítica sobre o seu próprio esquerdismo intelectual. Ele alude ainda ao facto de, por exemplo, a sua língua de atividade analítica intelectual ser o francês, e depois

\footnotetext{
${ }^{2}$ Esta reflexão pode ser escutada em maior detalhe num dos episódios do Blog e PodCast The Familiar Strange em que esta autora participou. Disponível em https://soundcloud.com/thefamiliarstrange/34knowledge-making-emma-kowal (acesso 16 Fevereiro 2021) e também no blog: https://thefamiliarstrange.com/2019/04/22/activist-anthropology/ (acesso 16 Fevereiro 2021)
} 
sobretudo o inglês, e a do seu posicionamento anti-israelita ser basicamente o árabe. Emma Kowal, a partir deste exemplo, propõe um posicionamento contextual no que diz respeito a assumir ou não uma antropologia ativista. Isto é, tudo depende do contexto (frase muito apreciada pelos antropólogos, afinal). Em boa verdade, esta ideia estava já contida no pensamento desenvolvido antes por Donna Haraway (1988) sobre conhecimento situado ao reconhecer que todo o conhecimento é localizado, parcial e incorporado e que por isso remete claramente para uma dimensão ética e política da produção do conhecimento científico (e de todo o conhecimento, de facto). Haraway demarca-se, portanto, de uma ciência não localizada, resultante de uma objetividade de lugar nenhum, sem responsibilização, e ainda dicotómica - distinguindo e afastando sujeito e objeto - e concebida finalmente como uma espécie de "teoria de poderes inocentes para representar o mundo" (Haraway, 1988: 579-580). Tal ponto de partida crítico permite que, simultaneamente, conceptualizemos a produção de conhecimento como um processo, dinâmico e suscetível de transformações e mudanças, e também como um olhar corporizado, não separado ou acima do objeto, mas reconhecendo nesse jogo de conhecer redes de conexão e distintas relações de poder que não passam por um mero relativismo ou por um essencialismo e universalismo epistemológico.

Concomitantemente, os meus interesses pelos aspetos performativos da atividade humana me conduziram a autores como Richard Schechner $(1985 ; 2002)$ ou Guillermo Gomez-Peña (2005), referências inultrapassáveis dos chamados Estudos da Performance, que reforçam o sentido político da performance não apenas como um modo de ver ou representar o mundo, mas também como um modo de agir sobre o mundo e, portanto, de fazer mundo. Diana Taylor (2013)2003, outra referência deste campo, sublinha ainda que a vantagem do termo performance (por relação, por exemplo, a outros termos como teatralidade ou drama) decorre do seu óbvio afastamento do pensamento e das referências ocidentais e eurocêntricas dada a sua intraduzibilidade cultural e na sua necessária recontextualização em cada local. Ora justamente, sempre procurei construir um itinerário que me levasse da performance política e do gesto performativo de dimensão política que a minha atividade como cidadão me impunha, até ao interior do pensamento crítico antropológico onde meus interesses intelectuais e académicos se consubstanciavam. Assim, cidadania, performance e antropologia se foram cruzando para mim de forma intensa e eminentemente política. 
Neste texto pretendo partilhar as estratégias e os itinerários utilizados na realização de três encontros ou cruzamentos entre arte, antropologia e ativismo que visavam conjugar tanto artistas quanto pesquisadores, num pano de fundo ligado a uma cidadania engajada. Refiro-me aos encontros internacionais que organizei sob o acolhimento institucional do Centro em Rede de Investigação em Antropologia (CRIA), junto com um vasto grupo de colegas: No Performance's Land? (2011), Arte e Política Reloaded (2016) e Corpos Dissidentes (2019). De encontro para encontro, como espero conseguir demonstrar, foram possíveis afinar, rever, expandir e explorar experimentalmente novas ruturas, novos modelos, novos itinerários, novas estratégias.

\title{
Cruzamentos instigantes entre arte, antropologia e ativismo
}

O antropólogo visual Christopher Wright afirmava em 2018, na famosa revista de teoria crítica Field:

\begin{abstract}
Arte, antropologia e ativismo são três disciplinas académicas, mas também tipos de ação, formas de produção cultural em si mesmas. (...) todas lidam com noções de realidades incertas: elas questionam o que constitui a realidade, usam realidade como algo material, e tentam afetar essa realidade e modificála. ${ }^{3}$
\end{abstract}

Antropologia seria assim uma forma de teorizar sobre a realidade social e também um método de aceder a essa realidade; o ativismo seria uma ferramenta para a agir e intervir ativamente sobre essa realidade; e, finalmente, com a "virada social" da arte contemporânea, esta não se preocuparia já e apenas com o interesse em criar a partir da realidade social ou em utilizá-la como uma espécie de matéria-prima em obras de arte, mas antes pressupunha que a arte pudesse intervir diretamente no social e alterá-lo positivamente. Curiosamente, Wright sublinhava que este triângulo disciplinar ganhou ainda mais fôlego com os cenários de crise que se foram instalando no mundo. ${ }^{4}$ Ora precisamente, os três eventos de que falo emergem também a partir de um cenário de crise que em Portugal se agravou particularmente no chamado período de intervenção da Troika (composta pelo Fundo Monetário Internacional, Banco Central Europeu e

\footnotetext{
3 Trad. minha, texto online em: http://field-journal.com/issue-11/uncertain-realities-art-anthropologyand-activism (último acesso 16 de fevereiro 2021)

${ }^{4}$ E acrescentaria eu que talvez essa mundialização dos cenários de crise de que fala esteja fundamentalmente assente num mundo mais a Ocidente e marcado por um atravessamento particular norte/sul
} 
Comissão Europeia), a partir da crise financeira e económica global - com os resgates na Grécia em 2010 e em Portugal em $2011^{5}$.

Christopher Wright afirma que se estamos a pensar na arte, antropologia e ativismo em relação a tempos de crise, se queremos que eles sejam incumbidos da tarefa de enfrentar a crise, então também precisamos de reconhecer as várias responsabilidades envolvidas. O autor fala de "responsabilidade situacional", uma posição em relação às particularidades sociais, políticas e económicas de um contexto específico e também uma atenção às particularidades criativas, imaginativas e afetivas desse mesmo contexto. Isso leva-nos a pensar também em uma particular atenção à ética do compromisso e da intervenção, seja do artista, do ativista ou do antropólogo. E, obviamente, essa ética emerge afinal através do processo de colaboração e engajamento intersubjetivo que se venha a revelar nas práticas antropológica, artística e ativista. Wright fala em éticas abertas e adaptativas. Isto significa pensar justamente que o processo de construção e desenho de pesquisa, intervenções artísticas ou ativistas reclamam formas de coresponsabilização, dialogadas e adaptadas situacionalmente por todos os intervenientes. Longe vai, portanto, a ideia de um antropólogo distanciado e neutral na relação com o objeto de pesquisa e com os seus sujeitos; do artista enquanto sujeito iluminado e solitário encerrado no seu atelier; ou do ativismo de liderança carismática, doutrinal e vertical.

A antropologia tem justamente vindo a pensar seriamente nesse engajamento dialógico com os seus interlocutores, nomeadamente na definição do design e do objeto de pesquisa, e não apenas nos impactos societais da investigação ou na devolução dos seus resultados aos contextos de análise. Nessa linha, Terence Turner em entrevista à revista Campos aludia a alguns riscos que um certo engajamento académico pode, mesmo assim, gerar, distanciando-se das agendas políticas que estavam na base dos movimentos sociais ou das reivindicações dos grupos estudados:

(...) nas tradições intelectuais antropológicas principais que nós temos no Ocidente (...) sempre houve um engajamento no sentido de formular programas de ação, de melhorar a sociedade, de dar à cultura formas mais capazes de promover o desenvolvimento de capacidades humanas. É verdade que uma vez convertidas em especialidades acadêmicas, muitas dessas teorias se tornam abstratas, ou abstraídas do contexto da luta social, cultural e ideológica no qual se originaram. (Lima et all, 2008:142)

\footnotetext{
${ }^{5}$ Portugal só em 2018 viria a saldar este "resgate", que foi, na verdade, um empréstimo com pesados juros; e a Grécia ainda não o saldou até hoje. Para o caso português sobre as políticas de austeridade e a intervenção da Troika e ver Moury e Freire 2013.
} 
Digamos que, tomado deste ponto de vista, a prática de produção de conhecimento antropológico está umbilicalmente associada aos modos de produção de mundos e aos processos de transformação social e cultural. E mesmo quando reduzida a modalidades clássicas internas à academia, os seus resultados, impactos e devires acabam sempre por, de um modo ou de outro, intercetarem-se com linhas de existência social das comunidades e dos indivíduos. De novo, a questão que se coloca como mais instigante é saber como essa interceção se faz? Que mecanismos éticos de engajamento encetar? Seguramente, não de forma top-down ou numa direção unívoca de especialista para/sobre agentes e sujeitos no mundo, mas antes talvez de forma dialógica, colaborativa, ainda que necessariamente tensional, entre antropólogos (ou académicos e intelectuais em senso lato) com a sociedade civil.

Uma vez mais, Wrigth traz-nos uma importante advertência:

\footnotetext{
Não estou a sugerir aqui que haja um conjunto vinculativo de ética previamente acordada, ou uma forma correspondente de responsabilidade, mas que a atuação no mundo implica necessariamente uma rede de envolvimentos com outros atores, e, portanto, a arte contemporânea, que afirma intervir positivamente e produtivamente em tempo de crise, precisa emergir com formas de responsabilidade situacional. ${ }^{6}$
}

Juntar antropologia, arte e ativismo pode implicar uma reconfiguração do processo criativo. Onde fica a criatividade nos tipos de intervenção social e ativismo que alguns artistas perseguem no e com o seu trabalho? Com o artista? Com os seus participantes/colaboradores? Com a cultura? Com a situação ou o contexto particular? Talvez o que seja necessário seja uma abertura a diferentes processos de criação, ou o desenvolvimento daquilo a que o antropólogo Steve Feld (1987) chama de "co-estético". Esse salto para a co-autoria, co-curadoria, co-criação parece ser tão vital ao artista, quanto ao ativista, quanto ainda ao antropólogo.

Assim, considero que arte, ativismo e antropologia e seus cruzamentos podem ser imaginados em, pelo menos, três dimensões:

Um primeiro cenário de interação penso que se poderá dar entre antropólogos, artistas e o universo dos movimentos sociais e suas pautas. Esse tem sido um campo bastante fértil e produtivo, com diversas variantes, mais ou menos engajadas, em temáticas tão diversas como os direitos humanos, sociais, religiosos, políticos,

\footnotetext{
${ }^{6}$ Ver nota $2($ trad. minha)
} 
identitários, indígenas, étnicos, etc., nas mais diversas dimensões da vida humana. Neste primeiro vicénio do século XXI, o ativismo político intercetou claramente o espaço académico, produzindo inúmeros eventos e espaços de diálogo entre intelectuais e representantes dos movimentos sociais, projetos e até ações políticas concretas em temas polémicos na vida das sociedades.

Um segundo contexto, mais tangencialmente intercetado, é o da presença $e$ diálogo entre academia e saberes tradicionais ou locais. No Brasil (e certamente noutros contextos) esta ligação tem sido explorada de múltiplas formas, em Portugal muito caminho está ainda por fazer. Especialistas convidados para trabalhar, lecionar, falar, estudar na academia ou projetos de extensão que se desenham nas comunidades locais com apoio de departamentos ou centros de pesquisa começam a ser instrumentos comuns usados nestas parcerias. Ong's, associações comunitárias e coletivos informais são muitas vezes os protagonistas mais diretamente envolvidos nestes processos que podem também convocar artistas e práticas artísticas. A dimensão agora explorada em alguns programas de financiamento internacionais em torno daquilo que se vem desenhando como ciência cidadã parece estar a ganhar algum espaço no meio académico, processo acelerado ainda mais pelo desenvolvimento de ferramentas e tecnologias digitais.

Finalmente, um último cenário, e que me toca particularmente, é aquele que tem mobilizado diretamente o diálogo entre o campo das artes e das práticas artísticas e a antropologia. Joseph Beuys, um dos fundadores do coletivo Fluxus, referência central na arte da performance, propôs bem cedo a noção de escultura social para falar do potencial transformador da $\operatorname{arte}^{7}$. E nem será preciso recordar aqui os debates intensos alimentados, entretanto, por Alfred Gell (2018)1998, Hal Foster (1995), Georges Marcus (2010), Arnd Schneider e Christopher Wright (2006), Els Lagrou (2007), Roger Sansi (2015), entre tantos outros, já para não introduzir as reflexões que na antropologia visual se fez e faz respeito às dimensões artísticas visuais e aos modos audiovisuais de fazer mundos ou a discussão sobre arte útil que reuniu entre muitos outros, a artista cubana Tania Bruguera e o museólogo britânico Alistair Hudson ${ }^{8}$. De facto, a transferência de conhecimento entre os campos da arte da antropologia e os interfaces estabelecidos entre práticas artísticas e etnográficas é já muito considerável. O interessante argumento de Roger Sansi (2015) em

\footnotetext{
${ }^{7}$ Para a discussão sobre esta proposta conceitual de Beuys ver Jordan, Cara M., (2017) Joseph Beuys and Social Sculpture in the United States (Phd Dissertion Art History). CUNY Academic Works. https://academicworks.cuny.edu/gc_etds/1731 (último acesso em 16 Fevereiro 2021)
} 
torno da teoria da dádiva como dispositivo conceptual para pensar a relação da arte contemporânea com o mundo contemporâneo, alicerçado nas dimensões colaborativas, na fluidez e na abolição de fronteiras entre artista e público, na co-autoria criativa e curatorial, é central. Por outro lado, a vivência etnográfica como dispositivo metodológico para a criação artística tem sido outro itinerário de cruzamento transdisciplinar e de campos.

Pois justamente os encontros que de 2011 em diante tenho vindo a propor e organizar e que gostaria agora finalmente de comentar sumariamente foram fruto destas interseções e questionamentos acima enumerados. E de algum modo podem ser pensados como modalidades de engajamento de uma certa antropologia pública.

\section{Os encontros: lugares, participações e campos de atuação}

Os lugares escolhidos (dentro e fora da academia), as participações em formato aberto (feitas através de convencionais papers académicos, mas também por instalações e performances, oficinas, apresentações de filmes, etc.), bem como a diversidade dos campos de atuação das pessoas convidadas a participar (artistas, ativistas, académicos), buscavam fazer abanar a "torre de marfim" universitária, e procuravam romper com discussões académicas sobre arte autocentradas em cenários intelectuais ou em campos disciplinares e profissionais legitimados e por vozes oficialmente consagradas. Provocando instabilidades reflexivas e expandindo o campo de diálogos e discussões a múltiplos modos de disseminar ciência e produzir conhecimento, estes encontros tentaram partilhar e promover formas colaborativas de produção dos eventos de forma a pluralizar tanto o acesso quanto o teor das mesmas. Escapar, ou pelo menos não se limitar, aos canais de financiamento habituais e tutelados pelas instituições oficiais e hegemónicas (agências nacionais de ciência, fundações, etc.) foi sendo cada vez mais evidente nos vários eventos propostos:

\section{\#1 Encontro - No performance Land? (2011) ${ }^{9}$}

Um Encontro entre artistas e antropólogos, com um pano de fundo politico, mas ainda sob grande vigilância e afinamento de uma importante fundação privada de arte e

\footnotetext{
${ }^{9}$ Para um pequeno trailer do evento ver: $\underline{\mathrm{https}: / / \text { vimeo.com/23164802 }}$
} 
cultura (Culturgest), com a colaboração de uma fundação de permuta cultural e cientifica (Fundação Luso-Americana) ou de embaixadas e da agência nacional de ciência (FCT) que procurou explorar as relações entre dentro e fora da academia, e sobretudo tentando visibilizar um lugar de fala dentro das instituições para os estudos da performance, numa tangente entre antropologia e arte. Talvez por esse enquadramento institucional ainda muito central, só foi possível assumir um programa separado de produtos culturais e artísticos (performances em palcos e galeria) e um outro de debates académicos antropológicos (em auditório na universidade). Ainda assim, duas performances se realizaram no interior do espaço académico convencional de auditório e uma outra nos corredores da universidade, o que levantou aliás alguns problemas logísticos e de segurança. Todavia, dimensões ligadas a imperativos legais físcais e à postura mercadorizada da cultura exigiram que os "espetáculos" tivessem cobrança de ingresso. Por outro lado, os performers receberam cachet, tendo sido os únicos participantes a usufruírem desse apoio financeiro garantido pela organização. Os restantes participantes obtiveram apoio das suas respetivas instituições académicas para as suas deslocações e estadias. Posteriormente, um livro coletivo com apoio institucional de uma editora da universidade federal brasileira e de um instituto de apoio à pesquisa a que estive ligado durante a minha estadia como Professor Visitante em 2009, conseguiu juntar reflexões resultantes do encontro, desta vez sem separação entre artistas e académicos. ${ }^{10}$

\section{\#2 Encontro, Arte e Política Reloaded (em 2016)}

Este encontro, assumiu já o perfil totalmente fora da academia, realizado num espaço cultural do circuito alternativo das artes performativas da cidade de Lisboa (Espaço da Penha) que reúne vários coletivos de performance, dança, arte urbana. Algumas performances também ocorreram numa outra associação cultural instalada naquele território (Hangar), sem cobrança de ingresso. Neste encontro procurou-se também estabelecer laços com organizações locais (associações e coletivos) que forneceram ao evento serviços alimentares (refeições) a preços controlados e baseados em conceções de soberania alimentar e alimentação saudável. Performers, ativistas e académicos/as fundiram-se aqui em debates, oficinas e apresentações performativas que

${ }^{10}$ RAPOSO, Paulo; DAWSEY, John; CARDOSO, Vânia Z.; FRADIQUE, Teresa Terra do não lugar: diálogos entre antropologia e performance. Florianópolis, EDUFSC, 2013 
resultaram em intensas discussões e partilhas. Deste evento resultaram redes e conexões que ativaram futuras colaborações entre os/as intervenientes (seja a nível artístico, ativista ou a nível académico); um ciclo de cinema documental que acontecia no Brasil (Cine Festival Tornado) teve ali uma sua extensão (a única que se realizou no interior do espaço universitário); uma performance que já tinha sido realizada em outros contextos fez ali mais uma aparição com outros intervenientes (Forças IV de Rodrick Steel); uma rede investigadores se estabeleceu para programar períodos de investigação e visitação de centros de pesquisa; e, finalmente, um livro sobre textos de arte socialmente comprometida nasceu a partir da seleção e tradução de dois dos organizadores que consumaram assim um percurso de diálogos ${ }^{11}$.

\#3 Encontro - Corpos Dissidentes, Cidades Rebeldes (2019) ${ }^{12}$

Definitivamente neste terceiro encontro abandonam-se os espaços convencionais da academia, bem como os espaços "alternativos" de um circuito cultural urbano marcado por um certo tipo de audiência, e entramos em territórios prolixos e polémicos da cidade, marcados pela segregação social, por processos de gentrificação, pelo reordenamento urbano alvo de especulação imobiliária, num espaço onde se experimentaram antes programas de habitação com arrendamento a baixo custo, e ainda pela descontinuidade urbano/rural. Neste território procurámos assumir algum compromisso colaborativo com instituições e associações locais (Biblioteca Municipal, Associação de Imigrantes, uma Casa Regional e um coletivo feminista de arte urbana). O Encontro ocorreu em espaços da freguesia de Marvila, na parte oriental de Lisboa, e as sessões foram organizadas em formatos diversos num ambiente de conversas e debates, de visionamento e discussão em torno de ensaios visuais e sonoros, de participação em performances, instalações e caminhadas e com várias oficinas; em suma, este Encontro assumiu uma dinâmica muito mais experimental, seminal e oficinal de co-criação coletiva. Tratou-se basicamente de uma vivência, de portas abertas a quem ali chegasse; buscando o fora do fora, i.e., a rua onde muitas atividades foram experimentadas e propostas; contatando com redes locais (embora a este respeito ainda tenha havido dificuldades em tornar central estas partilhas). Estes formatos destinavam-se a ser publicados online num webdoc em plataforma digital

\footnotetext{
${ }^{11}$ RAPOSO, Paulo; CASTELlANO, Carlos Garrido. Textos Para Uma Arte Socialmente Comprometida. Lisboa. Sistema Solar, 2019

${ }^{12}$ Para um pequeno trailer sobre o evento ver: https://vimeo.com/339619036
} 
criada para o evento, mas, infelizmente, esses resultados ainda aguardam por melhores dias para serem divulgados ${ }^{13}$. Talvez se possa assim concluir que o processo foi claramente mais relevante do que um qualquer produto que dali pudesse resultar.

\section{Notas quase finais}

Imagino agora que um caminho interessante para pensar uma antropologia engajada e de cruzamento com o ativismo e a arte, poderá ser o de levar às últimas consequências esta proposta de vivência coletiva que o \#3 encontro nos trouxe e assumir uma triangulação entre o modelo da residência artística, experimental e laboratorial para criação, com a noção trazida pelo ativismo político de zona autónoma temporária (TAZ de Hakim Bey(1985) ou de okupação ${ }^{14}$, junto com a experiência e o laboratório etnográfico que o terreno abre aos antropólogos e antropólogas num dado território. E, desta forma, sublinhar claramente, não as fronteiras entre estas três dimensões, mas as porosidades e transferências entre elas. Ampliar transfusões e trânsitos que permitam, por exemplo, encetar caminhadas performativas com sujeitos ou coletivos locais; criar paisagens e postais sonoros; desenhar oficinas e laboratórios de mapeamento crítico com população local explicitando trocas de saberes; programar projeções ao ar livre com debates, performances e instalações colaborativas; conceber refeições coletivas que alimentem heterotopias... este \#4 Encontro será talvez apenas isso: o encontro. Afinal, aquilo que fundamentalmente une antropólogas/os, artistas e ativistas.

\section{REFERÊNCIAS}

BEY, Hakim. Zona Autônoma Temporária (Tradução: Patrícia Decia e Renato Resende) Digitalização: Coletivo Sabotagem: Contra-Cultura, S.1., S.e., 2006. Disponível em: http://www.mom.arq.ufmg.br/mom/02_arq_interface/4a_aula/Hakim_Bey_TAZ.pdf (acesso em 17 Fevereiro 2021)

\footnotetext{
${ }^{13}$ Uma parte do evento está já inserido no webdoc Lisboa Oriental criado no Laboratório de Audiovisuais do CRIA por um grupo de estudantes da Pós-Graduação em Culturas Visuais Digitais sob orientação de Emiliano Dantas, Filipe Reis e eu próprio. Brevemente será disponibilizado no website do Centro em Rede de Investigação em Antropologia (CRIA) https://www.cria.org.pt/pt

${ }^{14}$ Para uma visão de conjunto do movimento okupa (squatter) na Europa ver MARTINEZ, 2013.
} 
GÓMEZ-PEÑA, Guillermo. "Em defesa del arte del performance". Horizontes Antropológicos, Porto Alegre, ano 11, n. 24, pp.199-226, 2005.

FELD, Steve. "Dialogic Editing: Interpreting How Kaluli Read 'Sound and Sentiment,"” Cultural Anthropology, Vol. 2, n. 2, pp.190-210, 1987.

FOSTER, Hal. "The artist as ethnographer?” In MARCUS, George e MYERS, Frank (ed.) The traffic in culture. Refiguring art and anthropology, Berkeley, LA e Londres, University of California Press, pp.302-309, 1995.

GELL, Alfred. Arte e Agência: uma teoria antropológica. (Trad. Jamille. Pinheiro Dias), São Paulo: Ubu Editora, (1998)2018.

HAGE, Ghassan. "Hating Israel in the Field: On ethnography and political emotions". In Anthropological Theory, Vol. 9, n .1, pp. 59-79, 2009.

HALE, Charles. "Activist Research v. Cultural Critique: Indigenous Land Rights and the Contradictions of Politically Engaged Anthropology". In Cultural Anthropology, Vol. 21, n.1, pp. 96-120, 2006.

HARAWAY, Donna. "Situated Knowledges: The Science Question in Feminism and the Privilege of Partial Perspective”. In Feminist Studies, Vol. 14, n.3, pp. 575-599, 1988.

JORDAN, Cara M. Joseph Beuys and Social Sculpture in the United States, Tese (Doutoramento em História de Arte). CUNY Academic Works, 2017.

Disponível em: https://academicworks.cuny.edu/gc_etds/1731 (acesso em 16 Fevereiro 2021)

JURIS, Jeffrey ; FEIXA, Carlos e PEREIRA, Inês.“La Globalización Alternativa y los Novísimos Movimientos Sociales”. In Revista del Centro de Investigación, Universidad La Salle, Vol. 10, n.37, pp. 23-39, 2012. 
LAGROU, Els. A fluidez da forma: arte, alteridade e agência em uma sociedade amazônica (Kaxinawa, Acre), Rio de Janeiro, TopBooks, 2007.

LIMA, Edilene Coffaci de; SMILJANIC, Maria Inês; FERNANDES, Ricardo Cid. "Uma Antropologia engajada: Entrevista com Terence Turner". In Campos- Revista de Antropologia, (S.1.) Vol. 9, n.2, pp.139-159, 2008.

MARCUS, George. "Contemporary Fieldwork Aesthetics in Art and Anthropology: Experiments in Collaboration and Intervention”. In Visual Anthropology, Vol.23, pp.263$277,2010$.

MARTINEZ, Miguel. “The Squatters' Movement in Europe: A Durable Struggle for Social Autonomy in Urban Politics”. In Antipode, Vol. 45, n.4, pp. pp 1-22, 2013.

MOURY, Catherine; FREIRE, André. “Austerity Policies and Politics:

The Case of Portugal”. In Pôle Sud, n 39, pp. 35-56, 2013.

OVERING, Joanna. “A estética da produção: o senso da comunidade entre os Cubeo e os Piaroa”. In Revista de Antropologia, Vol.34, pp. 7-34, 1991.

RAPOSO, Paulo; DAWSEY, John; CARDOSO, Vânia Z.; FRADIQUE, Teresa Terra do não lugar: diálogos entre antropologia e performance. Florianópolis, EDUFSC, 2013.

RAPOSO, Paulo; CASTELlANO, Carlos Garrido. Textos Para Uma Arte Socialmente Comprometida. Lisboa. Sistema Solar, 2019.

SANSI, Roger. Art, anthropology and the gift. London, Bloomsbury, 2015.

SCHECHNER, Richard. Between theater and anthropology. Philadelphia: University of Philadelphia Press, 1985.

SCHECHNER, Richard. Performance studies: an introduction. London and New York: Routledge, 2002. 
SCHNEIDER, Arnd, WRIGHT, Christopher. Contemporary Art and Anthropology. Oxford and New York, Berg, 2006.

TAYLOR, Diana. O arquivo e o repertório: performance e memória cultural nas Américas. Belo Horizonte: Editora UFMG, 2013.

WRIGHT, Christopher. "Uncertain Realities: Art, Anthropology, and Activism” In Field (11) 2018. Publicação online: http://field-journal.com/issue-11/uncertain-realities-artanthropology-and-activism (último acesso 16 Fevereiro 2021)

Recebido: 07/12/2020

Aprovado: 08/01/2021 